\title{
Transcutaneous electrical nerve stimulation after
} thoracic surgery: systematic review and metaanalysis of randomized trials

\author{
Estimulação elétrica nervosa transcutânea no pós-operatório de cirurgia torácica: revisão sistemática \\ e metanálise de estudos randomizados
}

\author{
Graciele Sbruzzi ${ }^{1}$, Scheila Azeredo Silveira ${ }^{2}$, Diego Vidaletti Silva ${ }^{2}$, Christian Correa Coronel ${ }^{3}$, \\ Rodrigo Della Méa Plentz ${ }^{4}$
}

DOI: $10.5935 / 1678-9741.20120012$

RBCCV 44205-1353

\section{Abstract}

Objectives: To evaluate the effects of transcutaneous electric nerve stimulation (TENS) on pain and pulmonary function during the postoperative period after thoracic surgery by performing a systematic review and meta-analysis of randomized trials.

Methods: The search strategy included MEDLINE, PEDro, Cochrane CENTRAL, EMBASE and LILACS, in addition to a manual search, from inception to August, 2011. Randomized trials were included, comparing TENS associated or not with pharmacological analgesia vs. placebo TENS associated or not with pharmacological analgesia or vs. pharmacological analgesia alone to assess pain (visual analog scale - VAS) and/or pulmonary function represented by forced vital capacity (FVC) in postoperative thoracic surgery patients (pulmonary or cardiac with approach by thoracotomy or sternotomy).

Results: Of the 2.489 articles identified, 11 studies were included. In the approach by thoracotomy, TENS associated with pharmacological analgesia reduced pain compared to

1. PhD, Post-doctoral research fellow in Health Science: Instituto de Cardiologia do Rio Grande do Sul/Fundação Universitária de Cardiologia, Porto Alegre, Brazil.

2. Physiotherapist, Porto Alegre, Brazil

3. MSc, Coordinator of the Specialization in Cardiopulmonary Physical Therapy and the Multidisciplinary Residency (Physiotherapy) of Instituto de Cardiologia do Rio Grande do Sul/Fundação Universitária de Cardiologia, Porto Alegre, Brazil.

4. ScD, Professor, Director of Physical Therapy Course of Universidade Federal de Ciências da Saúde de Porto Alegre, Brazil.

Study performed at Instituto de Cardiologia do Rio Grande do Sul/ Fundação Universitária de Cardiologia (IC/FUC) and Universidade Federal de Ciências da Saúde de Porto Alegre (UFCSPA), Porto Alegre, RS, Brazil. the placebo TENS associated with pharmacological analgesia (VAS -1.29; 95\% CI: -1.94 to - 0.65). In the approach by sternotomy, TENS associated with pharmacological analgesia also reduced pain compared to the placebo TENS associated with pharmacological analgesia (VAS -1.33; 95\% CI: -1.89 to $-\mathbf{0 . 7 7}$ ) and compared to pharmacological analgesia alone (VAS -1.23 ; 95\% CI: -1.79 to -0.67 ). There was no significant improvement in FVC $(0.12$ L; $95 \%$ CI: 0.27 to 0.51 ).

Conclusion: TENS associated with pharmacological analgesia provides pain relief compared to the placebo TENS in postoperative thoracic surgery patients both approached by thoracotomy and sternotomy. In sternotomy it also provides more effective pain relief compared to pharmacological analgesia alone, but it has no significant effect on pulmonary function.

Descriptors: Transcutaneous electric nerve stimulation. Thoracic surgery. Review.

Partially sponsored by Conselho Nacional de Desenvolvimento Científico e Tecnológico (CNPq) and Coordenação de Aperfeiçoamento de Pessoal de Nível Superior (CAPES).

Correspondence address

Rodrigo Della Méa Plentz

R Sarmento Leite, 245 - Porto Alegre, RS, Brazil.

Zip Code: $90050-170$

E-mail: roplentz@yahoo.com.br 


\begin{tabular}{|ll|}
\hline Abreviations, & acronyms \& symbols \\
\hline CAPES & $\begin{array}{l}\text { Coordenação de Aperfeiçoamento de Pessoal } \\
\text { de Nível Superior }\end{array}$ \\
CNPq & $\begin{array}{l}\text { Conselho Nacional de Desenvolvimento } \\
\text { Científico e Tecnológico }\end{array}$ \\
FVC & forced vital capacity \\
VAS & visual analog scale \\
RCTs & randomized clinical trials \\
CI & confidence interval \\
PEDro & Physiotherapy Evidence Database \\
PRISMA & Preferred Reporting Items for Systematic \\
TENS & Review and Meta-analyses \\
\hline
\end{tabular}

\section{Resumo}

Objetivo: Avaliar os efeitos da estimulação elétrica nervosa transcutânea (TENS) sobre a dor e a função pulmonar no pós-operatório de cirurgias torácicas por meio de uma revisão sistemática e metanálise de estudos randomizados.

Métodos: A busca incluiu as bases MEDLINE, PEDro, Cochrane CENTRAL, EMBASE e LILACS, além de busca manual, do início até agosto de 2011. Foram incluídos estudos randomizados comparando TENS associada ou não a analgesia farmacológica vs. TENS placebo associada ou não a analgesia farmacológica ou vs. analgesia farmacológica controlada, que avaliaram dor (por meio de escala analógica visual - EAV) e/ou função pulmonar representada pela capacidade vital forçada (CVF) em pacientes no pósoperatório de cirurgia torácica (pulmonar ou cardíaca com abordagem por toracotomia ou esternotomia).

Resultados: Dos 2.489 artigos identificados, 11 estudos foram incluídos. Na abordagem por toracotomia, a TENS associada à analgesia farmacológica reduziu a dor comparada com TENS placebo associada à analgesia farmacológica (EAV -1,29; IC95\%: -1,94 a - 0,65). Na abordagem por esternotomia, a TENS associada à analgesia farmacológica também reduziu a dor comparada a TENS placebo associada à analgesia farmacológica (EAV -1,33; IC95\% : -1,89 a -0,77) e comparada à analgesia farmacológica controlada (EAV-1,23; IC95\%: -1,79 a -0,67). Não foi observada melhora significativa na CVF $(0,12$ L; IC95\%: - 0,27 a 0,51).

Conclusão: A TENS associada à analgesia farmacológica promoveu maior alívio da dor comparada a TENS placebo em pacientes em pós-operatório de cirurgia torácica, tanto na abordagem por toracotomia quanto por esternotomia. $\mathrm{Na}$ esternotomia, também se mostrou mais efetiva que a analgesia farmacológica controlada no alívio da dor, porém sem efeito significativo na função pulmonar.

Descritores: Estimulação elétrica nervosa transcutânea. Cirurgia torácica. Revisão.

\section{INTRODUCTION}

Despite the technological developments observed in medicine and surgical area in general and the use of less invasive methods increasingly prominent, there is a huge number of diseases that require intervention with open surgical approach. Thoracic surgery has emerged in the late nineteenth century and progressed rapidly in the twentieth century, from the improvement of anesthesia, infection control and blood replacement [1]. These procedures are followed by methods for pain control, which aid in the recovery and quality of life of patients [2].

Thoracic surgeries are divided into two main types: lung and heart. In lung surgeries, the predominant surgical approach is via thoracotomy, as in cardiac surgery, median sternotomy is the most commonly used incision, being better for the exposure of the region, however, it can significantly alter lung function by the length of the incision and generate the resulting upper thorax instability [3].

The pain has been identified as a major source of concern for patients in the postoperative thoracic surgery, and it is known that the type of surgical approach generates different levels of pain [2]. This occurs for several reasons, such as incision, tissue retraction, use of chest tubes after surgery, location of drains and the inflammatory process. This clinical condition may collaborate with the increase in pulmonary complications in the postoperative period, such as decreased respiratory muscle strength, lung volumes and capacities, as well as reducing the effectiveness of cough and increased infections, which interfere in the patient evolution and are considered the main causes of morbidity and mortality in these cases [3-5].

There are differences in the intensity of pain in relation to the type of surgical approach. In a study of patients who underwent cardiac surgery, it was observed that the pain was not related to the type of surgical procedure (CABG, valve replacement and valve resection with partial involvement of the internal thoracic artery, saphenous vein and placement of metal valves) [3]. Mueller et al. [6] also found no difference in the characteristics of pain compared different types of surgery, even in deeper procedures. However, Benedetti et al. [2] found a difference in pain 
levels according to the type of surgical approach, demonstrating a greater perception of pain in the posterolateral thoracotomy approaches.

In addition to pharmacological analgesia, the eletroanalgesia has been proposed as an adjunctive treatment for the relief of postoperative pain, with consequent improvement of the mechanics of the chest cavity and reduction of possible respiratory complications in thoracic surgery. The transcutaneous electrical nerve stimulation (TENS) is a widely used feature in symptomatic relief of pain [7]. Thus, the stimulation can be used in routine postoperative hospital as an adjunct to conventional analgesia, because, in addition to being non-invasive and non-pharmacological, it is comfortable and some studies have found less need of using drugs to control pain [8].

However, there are divergent results between studies, Gregorini et al. [8] showed that TENS is effective in controlling pain in the postoperative period of cardiac surgery and provides improvement in respiratory muscle strength and increased lung volumes and capacities. On the other hand, Stubbing \& Jellicoe [9] showed that TENS did not change the pain of patients after thoracic surgery, creating the need for systematization of existing information.

Thus, the existence of several randomized controlled trials (RCTs) concerning the application of TENS with or without the use of drugs in the postoperative period of thoracic surgery approach with thoracotomy and sternotomy, the absence of systematic review studies encompassing approach sternotomy and the absence of meta-analysis justify the conduct of a recent systematic review on the subject [10]. The objective of this study was to evaluate the effects of TENS on pain and pulmonary function in the postoperative period of thoracic surgery (heart or pulmonary approach with posterolateral thoracotomy or median sternotomy) by means of systematic review and meta-analysis of RCTs.

\section{METHODS}

This study was approved by the Ethics Committee in Research of the Instituto de Cardiologia do Rio Grande do Sul / Fundação Universitária de Cardiologia, number 456410 , and follows the recommendations proposed by the Colaboração Cochrane [11] and Preferred Reporting Items for Systematic Review and Meta-Analyses: The PRISMA Statement [12].

\section{Eligibility Criteria}

We included RCTs with patients who underwent thoracic surgery (heart or pulmonary approach with posterolateral thoracotomy or median sternotomy) and were treated postoperatively with TENS with or without pharmacological analgesia compared to placebo TENS (electrical current dead) with or no pharmacological analgesia, or TENS associated with pharmacological analgesia vs. controlled pharmacological analgesia. The outcomes included were pain and pulmonary function represented by the forced vital capacity (FVC). We used the following exclusion criteria: studies with incomplete data and data from studies without control group. Articles that do not demonstrate the FVC in liters (L) were excluded from the meta-analysis.

\section{Search strategy}

We searched the electronic databases (from inception to August 2011): MEDLINE (accessed via PubMed), Physiotherapy Evidence Database (PEDro), Register of Controlled Trials (Cochrane CENTRAL), EMBASE and LILACS. In addition, we performed a manual search of references in published studies on the subject. The search was performed on August 29, 2011 and included the following words in English: "transcutaneous electric nerve stimulation," "eletric stimulation", "electric stimulation therapy," "thoracic surgery", "thoracic surgery procedures," "sternotomy" , "coronary artery bypass surgery", "myocardial revascularization", "aortic surgery", associated with a list of sensitive terms to search for RCTs, prepared by Robinson \& Dickersin [13], and their descriptors in Portuguese: estimulação elétrica nervosa transcutânea, estimulação elétrica, estimulação elétrica terapêutica, cirurgia cardíaca, procedimentos cirúrgicos cardíacos, esternotomia, cirurgia de revascularização do miocárdio, correção aórtica, ensaio clínico randomizado. The search strategy used to complete the PubMed can be seen in Table 1. There was no language restriction in the search.

\section{Study selection and data extraction}

The titles and abstracts of all articles identified by the search strategy were evaluated by two independent reviewers. All abstracts have not provided sufficient information on the inclusion and exclusion criteria were selected to evaluate the full text. In this second phase, the same reviewers independently assessed the full articles and made their selections, according to the eligibility criteria pre-specified. Disagreements between reviewers were resolved by consensus. The primary outcome was extracted pain measured by visual analog scale (VAS). The other outcome of interest was FVC, L. While the study did not have all the necessary data for meta-analysis, the corresponding author was contacted to request the missing data.

\section{Assessment of risk of bias}

The methodological quality assessment was performed by two investigators independently and took into consideration the following characteristics of included 

trials

studies: randomization sequence generation, allocation concealment, blinding, blinding of outcome assessors, intention to treat analysis and description of losses and exclusions. Studies without a clear description of these features were considered as unclear or not reporting the latter.

\section{Data analysis}

The meta-analysis was performed using random effects model and the measures of effect were obtained by postintervention values. The studies were analyzed separately from the surgical approach: studies in the surgical procedure were performed by thoracotomy posterolateral approach (analysis 1) and studies where the approach was by median sternotomy (analysis 2). Within these analyzes, we performed two comparisons: studies comparing TENS with or without pharmacological analgesia vs. TENS placebo with or without pharmacological analgesia and studies comparing TENS associated with pharmacological analgesia $v s$. controlled pharmacological analgesia.

It was considered a statistically significant alpha value $=0.05$. Statistical heterogeneity of treatment effect between the trials was assessed by testing and Q Cochran test inconsistency $\left(\mathrm{I}^{2}\right)$, in that values above $25 \%$ and $50 \%$ were considered indicative of moderate and high heterogeneity, respectively. All analyzes were conducted using software Review Manager 5.1 (Colaboração Cochrane) [11].

Sensitivity analyzes were conducted considering the characteristics of the included studies, meta-analyzes in which calculations have been redone, including only studies fulfilling certain criteria, such as patient age, duration of intervention and application of TENS, TENS application associated with pharmacological analgesia and pharmacological doses of analgesia.

Table 1. Search strategy used in PubMed

\#1 "Electric Stimulation"[Mesh] OR (Electrical Stimulation) OR (Electrical Stimulations) OR (Stimulation, Electrical) OR (Stimulations, Electrical) OR (Stimulation, Electric) OR (Electric Stimulations) OR (Stimulations, Electric)

\#2 "Transcutaneous Electric Nerve Stimulation"[Mesh] OR (Electrical Stimulation, Transcutaneous) OR (Stimulation, Transcutaneous Electrical) OR (Transcutaneous Electrical Stimulation) OR (Percutaneous Electric Nerve Stimulation) OR (Percutaneous Electrical Nerve Stimulation) OR (Transdermal Electrostimulation) OR (Electrostimulation, Transdermal) OR (Transcutaneous Electrical Nerve Stimulation) OR (Transcutaneous Nerve Stimulation) OR (Nerve Stimulation, Transcutaneous) OR (Stimulation, Transcutaneous Nerve) OR (Electric Stimulation, Transcutaneous) OR (Stimulation, Transcutaneous Electric) OR (Transcutaneous Electric Stimulation) OR (TENS) OR (Electroanalgesia) OR (Analgesic Cutaneous Electrostimulation) OR (Cutaneous Electrostimulation, Analgesic) OR (Electrostimulation, Analgesic Cutaneous)

\#3 "Electric Stimulation Therapy"[Mesh] OR (Therapeutic Electric Stimulation) OR (Electric Stimulation, Therapeutic) OR (Stimulation, Therapeutic Electric) OR (Therapy, Electric Stimulation) OR (Stimulation Therapy, Electric) OR (Electrotherapy)

\#4 \#1 OR \#2 OR \#3

\#5 $\quad$ "Thoracic Surgery"[Mesh] OR (Surgery, Thoracic) OR (Surgery, Cardiac) OR (Surgery, Heart) OR (Heart Surgery) OR (Cardiac Surgery)

\#6 "Thoracic Surgical Procedures"[Mesh] OR (Procedures, Thoracic Surgical) OR (Surgical Procedures, Thoracic) OR (Thoracic Surgical Procedure) OR (Procedure, Thoracic Surgical) OR (Surgical Procedure, Thoracic)

\#7 "Sternotomy"[Mesh] OR (Sternotomies) OR (Median Sternotomy) OR (Median Sternotomies) OR (Sternotomies, Median) OR (Sternotomy, Median)

\#8 "Coronary Artery Bypass"[Mesh] OR "Coronary Artery Bypass Grafting" OR "Coronary Artery Bypass Surgery" OR "Bypass, Coronary Artery" OR "Artery Bypass, Coronary" OR "Artery Bypasses, Coronary" OR "Bypasses, Coronary Artery" OR "Coronary Artery Bypasses" OR "Aortocoronary Bypass" OR "Aortocoronary Bypasses" OR "Bypass, Aortocoronary" OR "Bypasses, Aortocoronary" OR "Bypass Surgery, Coronary Artery"

\#9 "Myocardial Revascularization"[Mesh] OR "Myocardial Revascularizations" OR "Revascularization, Myocardial" OR "Revascularizations, Myocardial" OR "Internal Mammary Artery Implantation"

\#10 "Aortic surgery"

\#11 \#5 OR \#6 OR \#7 OR \#8 OR \#9 OR \#10

\#12 (randomized controlled trial[pt] OR controlled clinical trial[pt] OR randomized controlled trials[mh] OR random allocation[mh] OR double-blind method[mh] OR single-blind method[mh] OR clinical trial[pt] OR clinical trials[mh] OR ("clinical trial"[tw]) OR ((sing1*[tw] OR doubl*[tw] OR trebl*[tw] OR tripl*[tw]) AND (mask*[tw] OR blind*[tw])) OR ("latin square"[tw]) OR placebos[mh] OR placebo*[tw] OR random*[tw] OR research design[mh:noexp] OR follow-up studies[mh] OR prospective studies[mh] OR cross-over studies[mh] OR control*[tw] OR prospectiv*[tw] OR volunteer*[tw]) NOT (animal[mh] NOT human[mh]) 


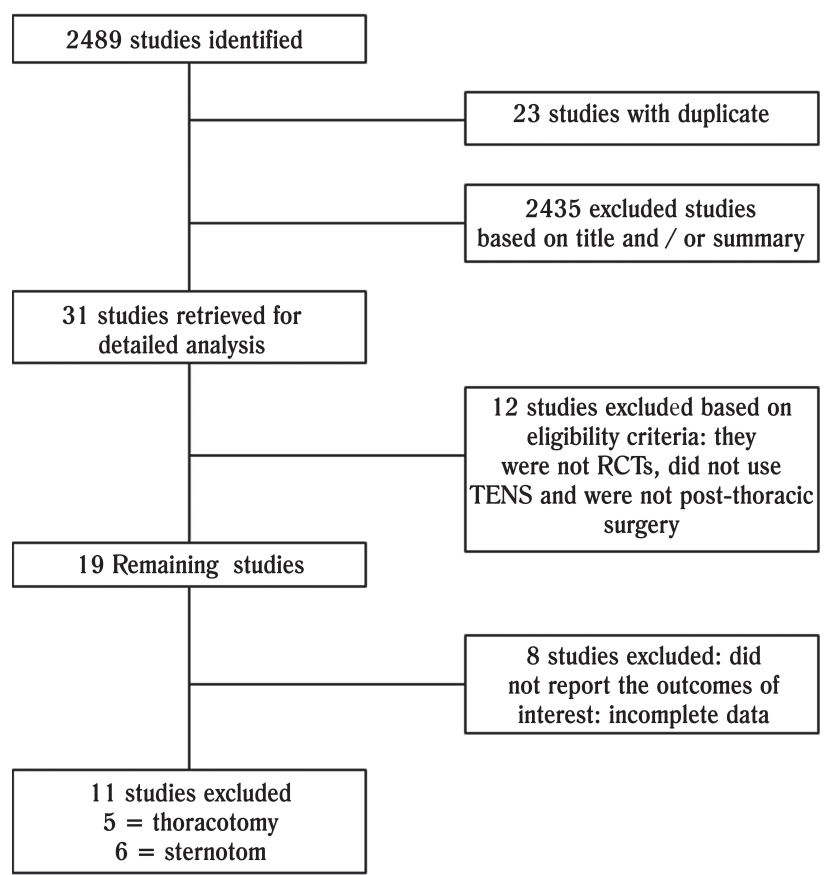

Fig. 1 - Flowchart of studies included in the review.

$R C T=$ randomized clinical trial; TENS = Transcutaneous electric nerve stimulation

\section{RESULTS}

\section{Description of studies}

The initial search identified 2489 articles, of which 31 studies were retrieved for detailed analysis. Of these, 19 were considered potentially relevant. However, eight studies were excluded for not reporting the outcomes of interest $[2,9,14]$, due to missing data or incomplete data for the metaanalysis [8,15-17] or for failing to control group according to inclusion criteria [18], leaving 11 articles included in the meta-analysis, a total of 570 patients. Of these, five items were related to lung surgery with posterolateral thoracotomy approach [19-23] and six studies underwent cardiac surgery with median sternotomy approach [4,24-28]. Figure 1 shows the flowchart of studies included and Table 2 summarizes the characteristics of these studies.

\section{Risk of bias}

In the five studies that pulmonary surgery with posterolateral thoracotomy approach [19-23], only one was blinded and had blinding of assessors of outcomes [20]. None of the studies presented description of random sequence generation, allocation concealment, description of losses and exclusions and analysis by intention to treat. Among the six studies that performed cardiac surgery with

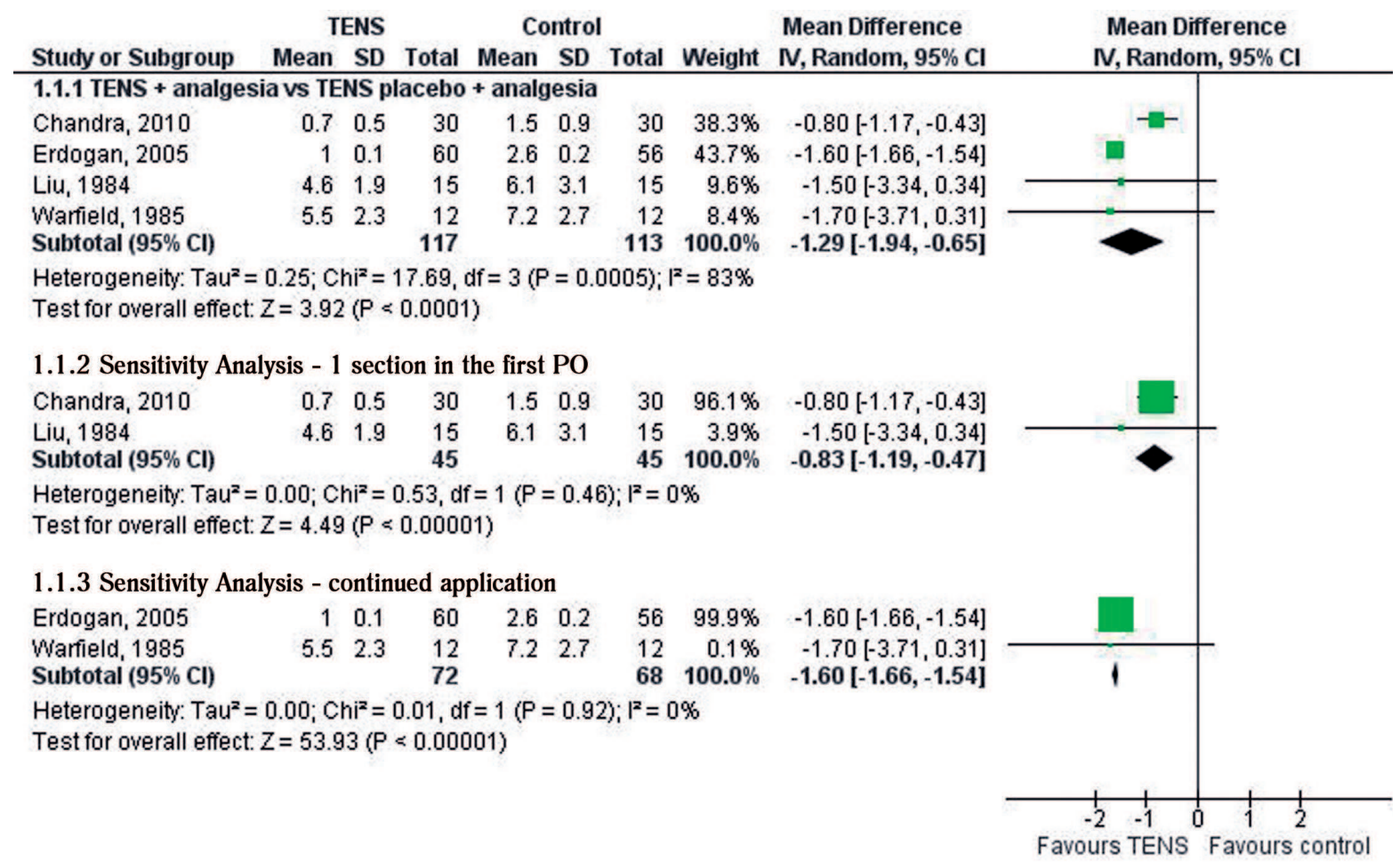

Fig. 2 - Analysis of pain related to studies that performed surgery with posterolateral thoracotomy approach: comparison of TENS + analgesia vs Placebo TENS + analgesia; TENS = Transcutaneous electric nerve stimulation 


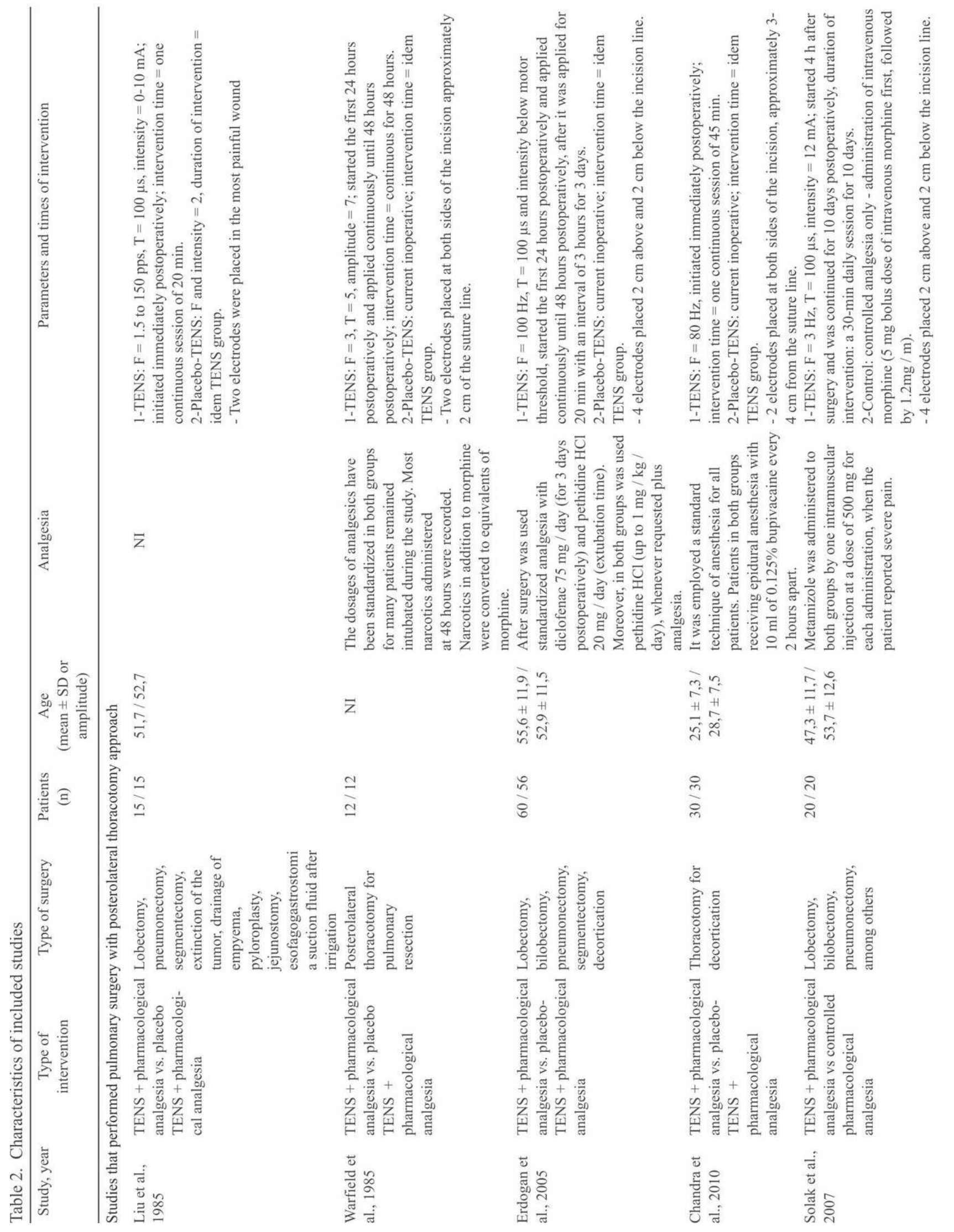




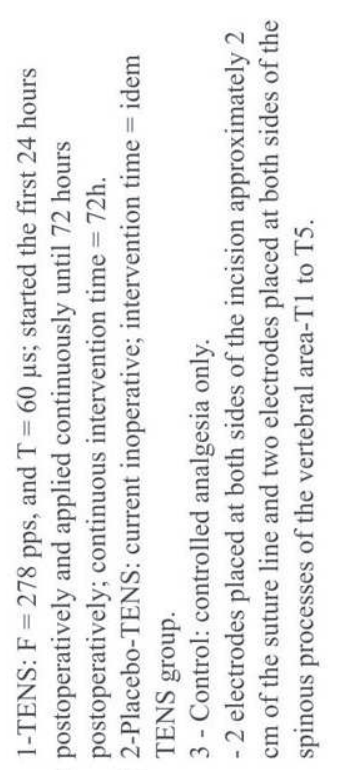

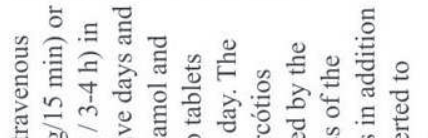

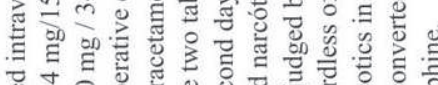

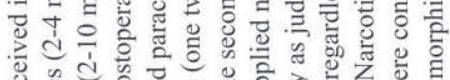

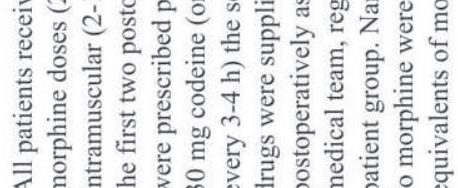

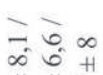

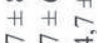 \\ की}

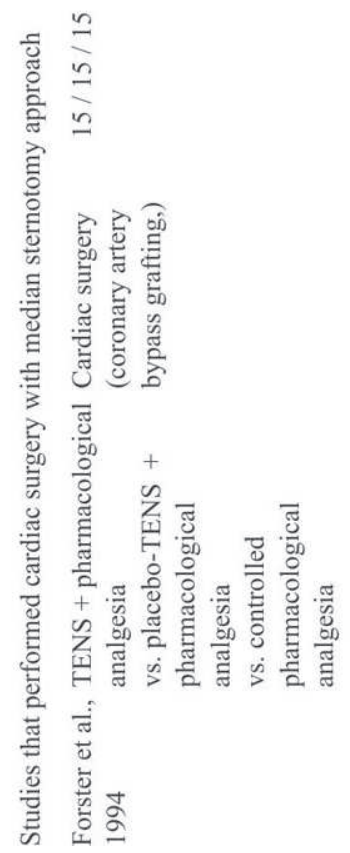

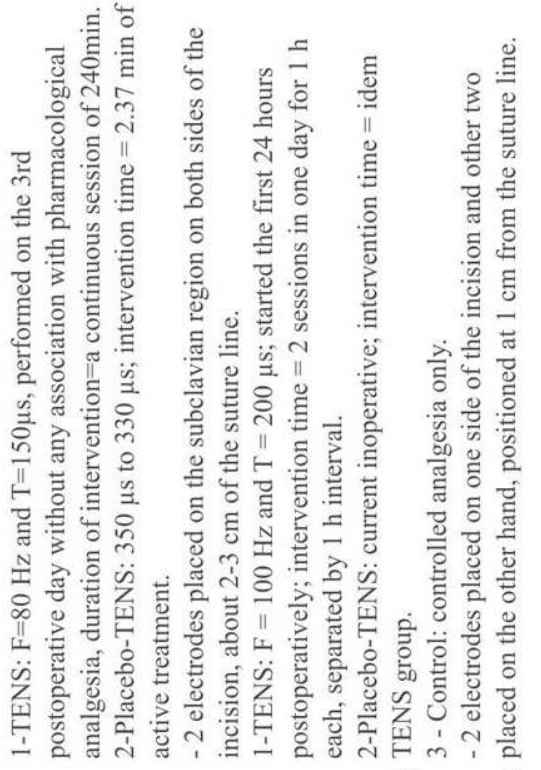
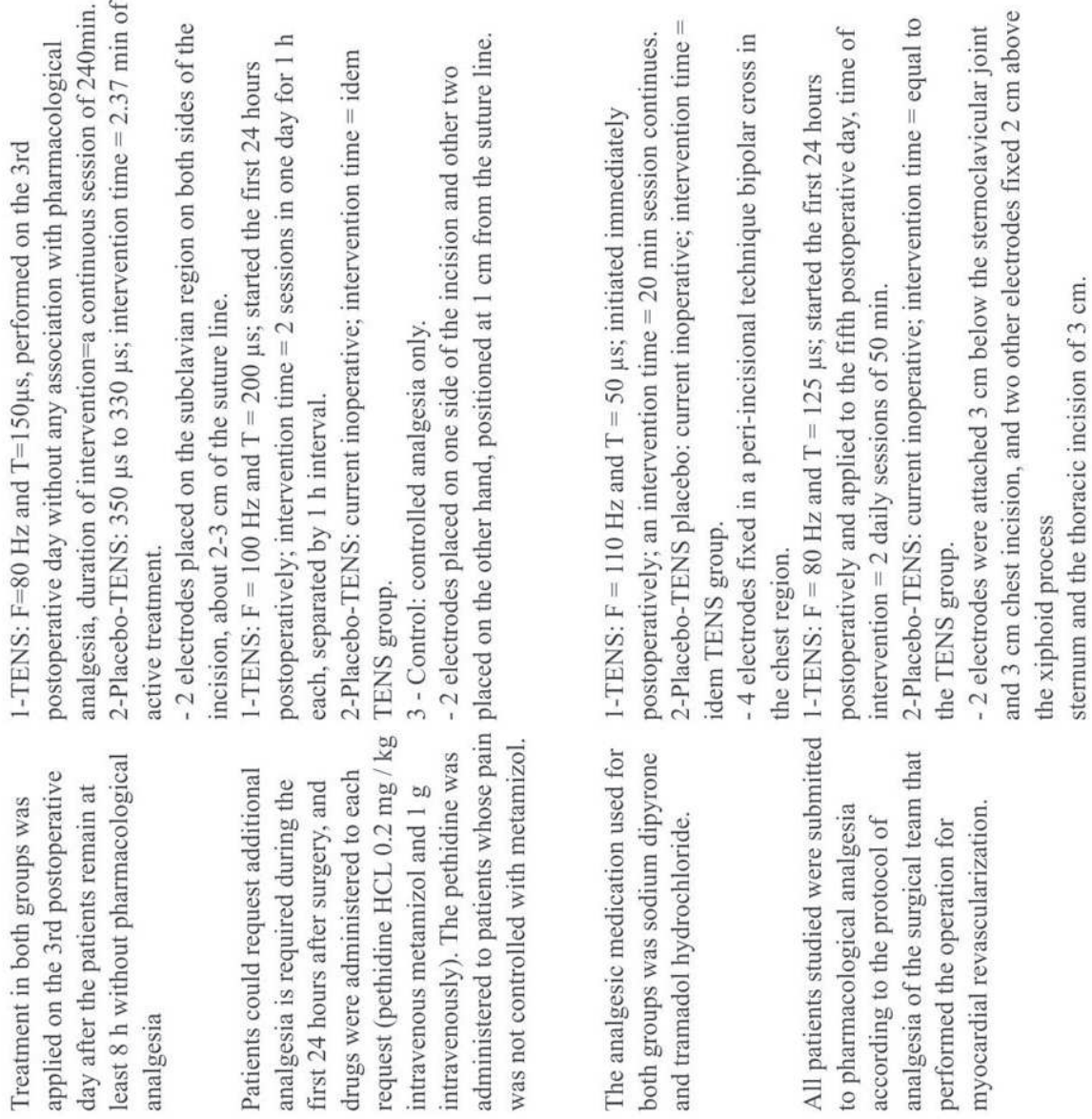

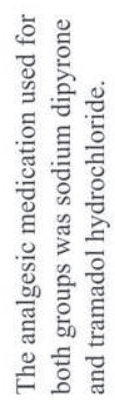
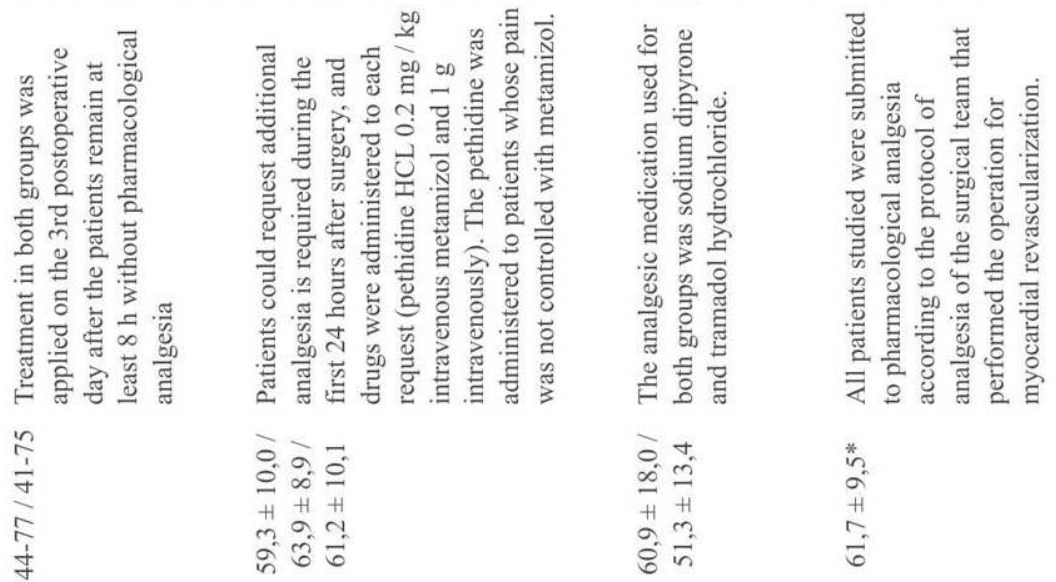

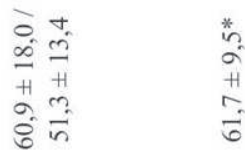

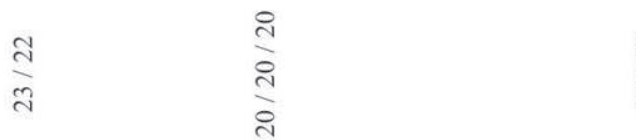

$\stackrel{n}{\circ} \quad \frac{n}{n}$
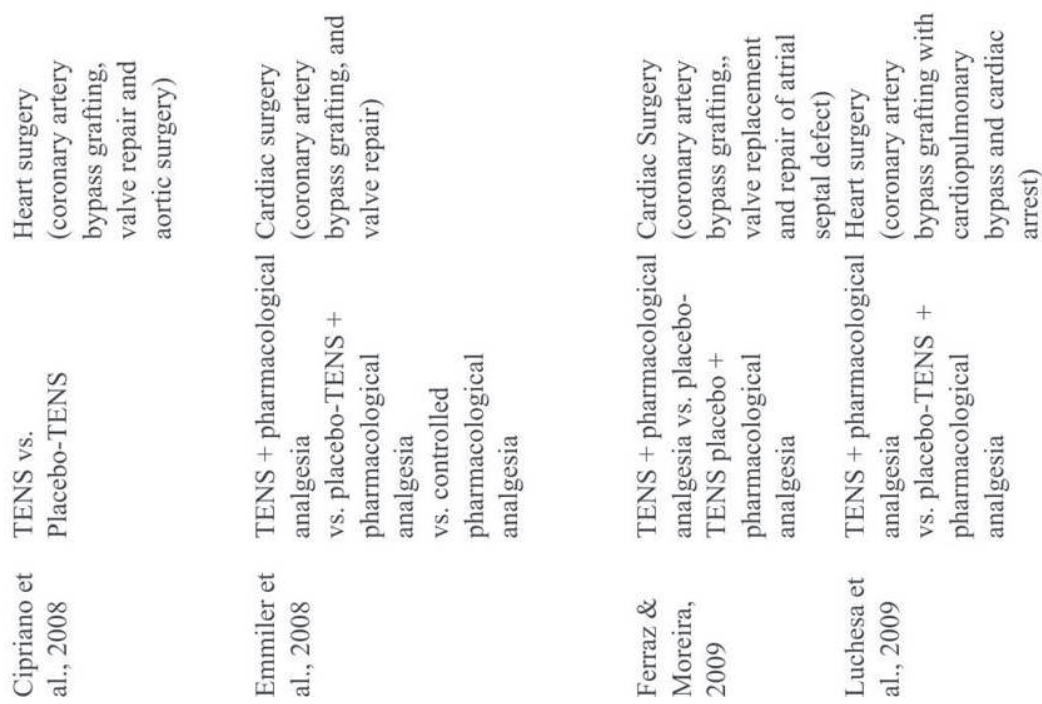
Solak et al., TENS + pharmacological Heart surgery analgesia (coronary artery

vs. placebo-TENS $+\quad$ bypass grafting with pharmacological left internal

analgesia mammary artery or

vs. controlled saphenous vein)

pharmacological

analgesia
$25 / 25 / 25 \quad 64,5 \pm 6,9 / 65$ Metamizol (500 mg

l-TENS-continuous: $\mathrm{F}=100 \mathrm{~Hz}$ and $\mathrm{T}=100 \mu \mathrm{s}$; continuously use

$64,9 \pm 7,3$

intramuscularly) was administered the first 24 hours postoperatively; continuous intervention time $=$

to all patients in all groups during $24 \mathrm{~h}$

the first $24 \mathrm{~h}$ after surgery.cirurgia. 2-Placebo-TENS: current inoperative; intervention time $=$ idem TENS group.

3 - Control: controlled analgesia only: a standard solution of morphine sulfate $(1 \mathrm{mg} / \mathrm{ml})$.

-2 electrodes placed on one side of the incision and other two placed on the other hand, positioned at $1 \mathrm{~cm}$ from the suture line.

*Studies do not report separately the mean \pm SD age and number of male patients for TENS versus the control group. / TENS versus the control group. SD - standard deviation, $F$-frequency of stimulation, $T$-Pulse time; NI - not informed; PO-post-operative TENS - transcutaneous electrical nerve stimulation, FVC-forced vital capacity

Table 3. Assessment of risk of bias

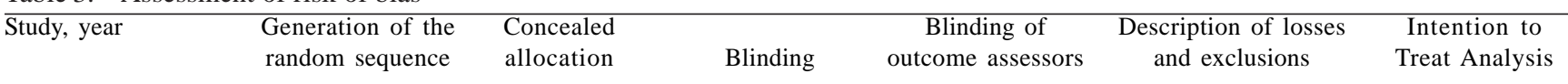

Studies that performed pulmonary surgery with posterolateral thoracotomy approach

\begin{tabular}{|c|c|c|c|c|c|c|}
\hline Liu et al., 1985 & Not informed & Not informed & Not informed & Not informed & Not informed & Not informed \\
\hline Warfield et al., 1985 & Not informed & Not informed & Not informed & Not informed & No & Not informed \\
\hline Erdogan et al., 2005 & Not informed & Not informed & Yes & Yes & No & Not informed \\
\hline Solak et al., 2007 & Not informed & Not informed & Not informed & Not informed & No & Not informed \\
\hline Chandra et al., 2010 & Not informed & Not informed & Not informed & Not informed & No & $\begin{array}{l}\text { Not informed } \\
\text { Not informed }\end{array}$ \\
\hline \multicolumn{7}{|c|}{ Studies that performed cardiac surgery with median sternotomy approach } \\
\hline Forster et al., 1994 & Not informed & Not informed & Not informed & Not informed & Yes & Not informed \\
\hline Cipriano et al., 2008 & Not informed & Not informed & Not informed & Not informed & No & Not informed \\
\hline Emmiler et al., 2008 & Yes & Not informed & Not informed & Not informed & No & No \\
\hline Ferraz \& Moreira, 2009 & Yes & Yes & Not informed & Not informed & Not informed & Not informed \\
\hline Luchesa et al., 2009 & Not informed & Not informed & Yes & Yes & Yes & No \\
\hline Solak et al., 2009 & Yes & Not informed & Not informed & Not informed & Not informed & Not informed \\
\hline
\end{tabular}



trials

median sternotomy approach [4,24- 28], 50\% had a description of adequate random sequence generation, $17 \%$, was the allocation concealment, had blinded and blinding of outcome assessors and $33 \%$ reported losses and exclusions. None of the studies performed intention-totreat analysis (Table 3).

\section{Effects of interventions}

\section{Analysis 1 - Studies that performed pulmonary surgery with posterolateral thoracotomy approach}

\section{Pain}

Five studies [19-23] performed pulmonary thoracic surgery posterolateral thoracotomy approach and assessed pain postoperatively. Of these, four studies [19-21,23] compared TENS associated with pharmacological analgesia versus placebo TENS associated with pharmacological analgesia. In this comparison, we found that TENS provided significant reduction in pain compared to placebo TENS [-
$1.29 ; 95 \%$ confidence interval ( $95 \% \mathrm{CI}):-1.94$ to $-0.65, \mathrm{I}^{2}$ : 83\%] (Figure 2).

Due to the high statistical heterogeneity observed, we performed sensitivity analysis with respect to time of intervention, which were separately analyzed the studies in which TENS was applied in a single session on the first day after surgery [19,21] and studies in which TENS was applied continuously for 48 hours or more [20,23]. In both situations, it was observed that TENS significantly reduced pain compared to placebo TENS [(-0.83, 95\% CI: -1.19 to -0.47$)$ and (-1.60, 95\% CI: -1.66 to -1.54$)$, respectively] with absence of heterogeneity $\left(\mathrm{I}^{2} 0 \%\right)$ (Figure 2$)$. It was also analyzed for sensitivity to the age of the patients since the study of Chandra et al. [19] presented a mean age of 27 years, which differs from other studies in which the average age was 52 years. Excluding this study from the analysis, we found that patient age did not alter the observed result, but may have been a causative factor of statistical heterogeneity, because the exclusion of this study noted the absence of heterogeneity $\left(-1.6 ; 95 \% \mathrm{CI}:-1.66\right.$ to $\left.-1.54, \mathrm{I}^{2}: 0 \%\right)$.

\begin{tabular}{|c|c|c|c|c|c|c|c|c|c|c|c|}
\hline \multirow[b]{2}{*}{ Study or Subgroup } & \multicolumn{3}{|c|}{ TENS } & \multicolumn{3}{|c|}{ Control } & \multicolumn{3}{|c|}{ Mean Difference } & \multirow{2}{*}{\multicolumn{2}{|c|}{$\begin{array}{l}\text { Mean Difference } \\
\text { IV, Random, } 95 \% \mathrm{Cl}\end{array}$}} \\
\hline & Mean & SD & Total & Mean & SD & Total & Weight & IV, Random, $95 \% \mathrm{Cl}$ & Year & & \\
\hline \multicolumn{12}{|c|}{ 1.2.1 TENS vs TENS placebo } \\
\hline Foster, 1994 & 1 & 1.8 & 15 & 1.3 & 1.6 & 15 & $12.3 \%$ & $-0.30[-1.52,0.92]$ & 1994 & & \\
\hline Cipriano, 2008 & 2 & 1 & 23 & 3 & 2.2 & 22 & $15.2 \%$ & $-1.00[-2.01,0.01]$ & 2008 & & \\
\hline Emmiler, 2008 & 1.2 & 0.9 & 20 & 2.3 & 1.3 & 20 & $20.4 \%$ & $-1.10[-1.79,-0.41]$ & 2008 & & \\
\hline Ferraz \& Moreira, 2009 & 1.8 & 0.8 & 10 & 2.9 & 1.7 & 10 & $13.0 \%$ & $-1.10[-2.26,0.06]$ & 2009 & & \\
\hline Luchesa, 2009 & 0.5 & 0.6 & 15 & 2.1 & 1.5 & 15 & $18.2 \%$ & $-1.60[-2.42,-0.78]$ & 2009 & & \\
\hline Solak, 2009 & 4.1 & 0.8 & 25 & 6.4 & 1.5 & 25 & $20.9 \%$ & $-2.30[-2.97,-1.63]$ & 2009 & & \\
\hline Subtotal $(95 \% \mathrm{Cl})$ & & & 108 & & & 107 & $100.0 \%$ & $-1.33[-1.89,-0.77]$ & & & \\
\hline \multicolumn{12}{|c|}{$\begin{array}{l}\text { Heterogeneity: } \text { Tau }^{2}=0.27 ; \mathrm{Chi}^{2}=11.89, \mathrm{df}=5(\mathrm{P}=0.04) ; \mathrm{I}^{2}=58 \% \\
\text { Test for overall effect: } Z=4.66(P<0.00001)\end{array}$} \\
\hline \multicolumn{12}{|c|}{ 1.2.2 Sensitivity Analysis - TENS + analgesia vs TENS placebo + analgesia } \\
\hline Foster, 1994 & 1 & 1.8 & 15 & 1.3 & 1.6 & 15 & $15.1 \%$ & $-0.30[-1.52,0.92]$ & 1994 & & \\
\hline Emmiler, 2008 & 1.2 & 0.9 & 20 & 2.3 & 1.3 & 20 & $23.6 \%$ & $-1.10[-1.79,-0.41]$ & 2008 & & \\
\hline Solak, 2009 & 1.8 & 0.8 & 10 & 2.9 & 1.7 & 10 & $15.8 \%$ & $-1.10[-2.26,0.06]$ & 2009 & & \\
\hline Luchesa, 2009 & 0.5 & 0.6 & 15 & 2.1 & 1.5 & 15 & $21.4 \%$ & $-1.60[-2.42,-0.78]$ & 2009 & & \\
\hline $\begin{array}{l}\text { Ferraz \& Moreira, } 2009 \\
\text { Subtotal }(95 \% \mathrm{Cl})\end{array}$ & 4.1 & 0.8 & $\begin{array}{l}25 \\
85\end{array}$ & 6.4 & 1.5 & $\begin{array}{l}25 \\
85\end{array}$ & $\begin{array}{r}24.1 \% \\
100.0 \%\end{array}$ & $\begin{array}{l}-2.30[-2.97,-1.63] \\
-1.38[-2.02,-0.73]\end{array}$ & 2009 & & \\
\hline \multicolumn{12}{|c|}{$\begin{array}{l}\text { Heterogeneity: } \mathrm{Tau}^{2}=0.33 ; \mathrm{Chi}^{2}=11.05, \mathrm{df}=4(\mathrm{P}=0.03) ; \mathrm{I}^{2}=64 \% \\
\text { Test for overall effect: } Z=4.18(\mathrm{P}<0.0001)\end{array}$} \\
\hline \multicolumn{12}{|c|}{ 1.2.3 Sensitivity Analysis - 1 section in the first PO } \\
\hline Emmiler, 2008 & 1.2 & 0.9 & 20 & 2.3 & 1.3 & 20 & $73.8 \%$ & $-1.10[-1.79,-0.41]$ & 2008 & & \\
\hline $\begin{array}{l}\text { Ferraz \& Moreira, } 2009 \\
\text { Subtotal }(95 \% \mathrm{CI})\end{array}$ & 1.8 & 0.8 & $\begin{array}{l}10 \\
30\end{array}$ & 2.9 & 1.7 & $\begin{array}{l}10 \\
30\end{array}$ & $\begin{array}{r}26.2 \% \\
100.0 \%\end{array}$ & $\begin{array}{r}-1.10[-2.26,0.06] \\
-1.10[-1.70,-0.50]\end{array}$ & 2009 & & \\
\hline \multicolumn{12}{|c|}{$\begin{array}{l}\text { Heterogeneity: } \text { Tau }^{2}=0.00 ; \mathrm{Chi}^{2}=0.00, \mathrm{df}=1(\mathrm{P}=1.00) ; \mathrm{I}^{2}=0 \% \\
\text { Test for overall effect: } Z=3.62(\mathrm{P}=0.0003)\end{array}$} \\
\hline
\end{tabular}

Fig. 3 - Analysis of pain related to studies that performed surgery with median sternotomy approach: comparison of TENS vs. placebo TENS; TENS $=$ transcutaneous electrical nerve stimulation 
Still, one study [22] compared TENS associated with pharmacological analgesia versus controlled pharmacological analgesia where it was observed that treatment with TENS associated with pharmacological was no more effective in reducing pain $(-0.5,95 \% \mathrm{CI}:-1.27$ to 0.27) compared to controlled pharmacological analgesia postoperative surgery with posterolateral thoracotomy approach.

\section{Analysis 2 - Study that performed cardiac surgery with median sternotomy approach}

Pain

Six studies $[4,24-28]$ performed cardiac thoracic surgery with median sternotomy approach and assessed pain postoperatively. Five of the studies [4,25-28] compared TENS associated with pharmacological analgesia versus placebo TENS associated with pharmacological analgesia and one study [24] compared TENS versus placebo TENS without association with pharmacological analgesia. Considering all studies together, it was observed that TENS provided significant reduction in pain compared to placebo TENS (-1.33, 95\% CI: -1.89 to $\left.-0.77, \mathrm{I}^{2}: 58 \%\right)$. Except for the analysis of the study Cipriano et al. [24], which did not associate the use of TENS with pharmacological analgesia, there was no change in result (-1.38, 95\% CI: -2.02 to -0.73$)$. We performed a sensitivity analysis with respect to time of intervention, which analyzed separately the studies that
TENS was applied in a single session on the first day after surgery $[25,26]$ also observed a significant reduction in pain compared placebo TENS , with no heterogeneity (1.10, 95\% CI: -1.70 to -0.50) (Figure 3).

Among these six studies, three $[4,25,28]$ had a third group that performed only controlled pharmacological analgesic, and it is possible to compare TENS associated with pharmacological analgesia versus controlled pharmacological analgesia. In this analysis, it was observed that TENS associated with pharmacological analgesia reduced pain compared to controlled pharmacological analgesia (-1.23, 95\% CI: -1.79 to $\left.-0.67, \mathrm{I}^{2}: 32 \%\right)$ (Figure 4). We performed sensitivity analysis with respect to time of intervention, which analyzed separately the studies that TENS was applied continuously in the postoperative period [4,28], thus excluding the study of Emmiler et al. [25] and also observed a reduction in pain compared TENS versus controlled pharmacological analgesia $(-1.54,95 \%$ CI: -2.16 to $-0.92, I^{2}: 0 \%$ ) (Figure 4).

It was not necessary to perform sensitivity analysis in relation to age of the patients, as patients from all studies included had an average age of 60 years.

\section{Forced vital capacity}

Two trials compared TENS versus placebo TENS in FVC $[24,28]$. We observed no significant difference between the two interventions [0.12 L, 95\% CI: -0.27 to $0.51, \mathrm{I}^{2}: 80 \%$ ] (Figure 5).

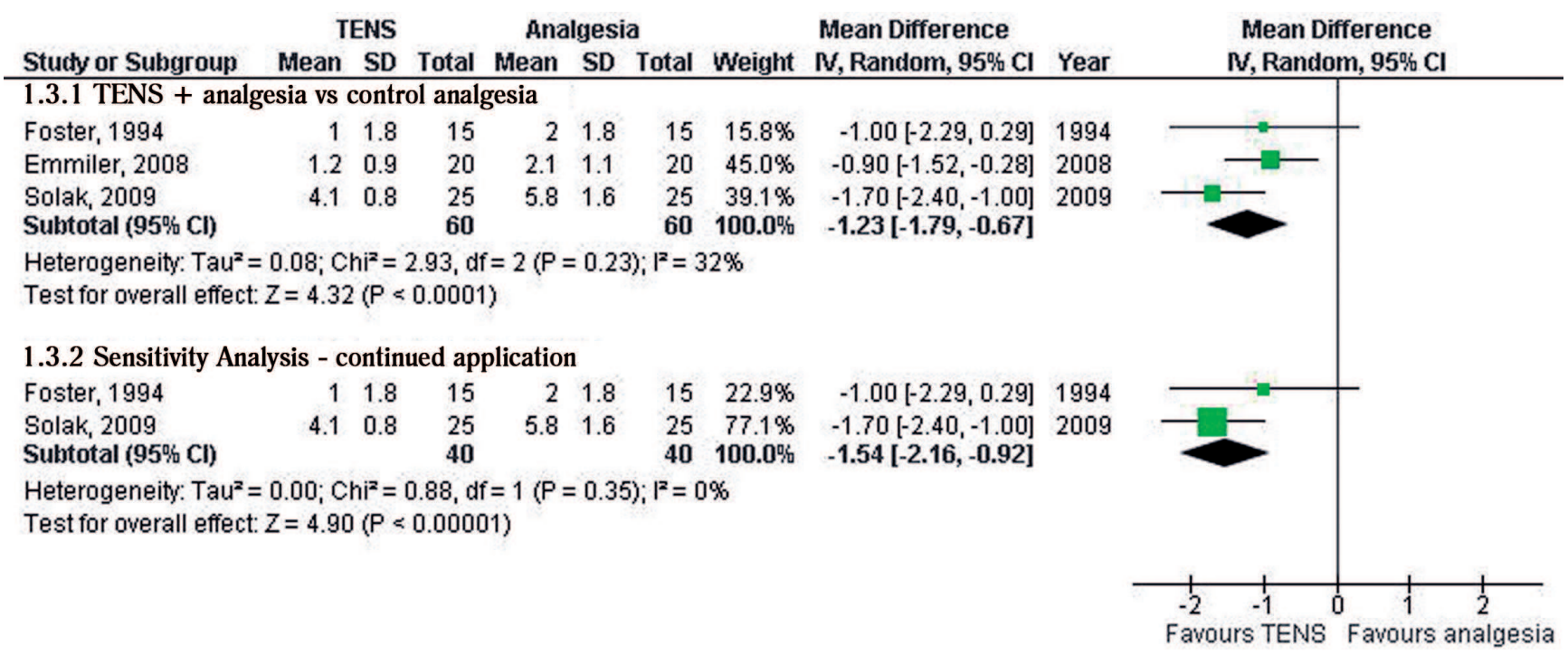

Fig. 4 - Analysis of pain related to studies that performed surgery with median sternotomy approach: comparison of TENS + pharmacological analgesia vs. controlled pharmacological analgesia; TENS - transcutaneous electrical nerve stimulation 


\begin{tabular}{|c|c|c|c|c|c|c|c|c|c|}
\hline \multirow[b]{2}{*}{ Study or Subgroup } & \multicolumn{3}{|c|}{ TENS } & \multicolumn{3}{|c|}{ TENS placebo } & \multirow[b]{2}{*}{ Weight } & \multirow{2}{*}{$\begin{array}{l}\text { Mean Difference } \\
\text { IV, Random, } 95 \% \mathrm{Cl}\end{array}$} & \multirow{2}{*}{$\begin{array}{c}\text { Mean Difference } \\
\text { N, Random, } 95 \% \mathrm{Cl}\end{array}$} \\
\hline & Mean & SD & Total & Mean & SD & Total & & & \\
\hline Cipriano, 2008 & 1.8 & 0.4 & 23 & 1.9 & 0.6 & 22 & $45.2 \%$ & $-0.10[-0.40,0.20]$ & \\
\hline Solak, 2009 & 1.9 & 0.2 & 25 & 1.6 & 0.4 & 25 & $54.8 \%$ & $0.30[0.12,0.48]$ & \\
\hline Total $(95 \% \mathrm{Cl})$ & & & 48 & & & 47 & $100.0 \%$ & $0.12[-0.27,0.51]$ & \\
\hline $\begin{array}{l}\text { Heterogeneity: Tau }{ }^{2} \\
\text { Test for overall effec }\end{array}$ & $\begin{array}{l}0.06 ; C \\
Z=0.60\end{array}$ & $\begin{array}{l}h^{2}= \\
(P=\end{array}$ & $\begin{array}{l}5.11, d \\
0.55)\end{array}$ & $f=1(P$ & 0 & $=$ & & & $\begin{array}{ccccc}1 & 1 & 1 & 1 & 1 \\
-1 & -0.5 & 0 & 0.5 & 1 \\
\text { Favours control } & \text { Favours TENS }\end{array}$ \\
\hline
\end{tabular}

Fig. 5 - Analysis of forced vital capacity refers to studies that performed surgery with median sternotomy approach: comparison of TENS vs. placebo TENS; TENS = transcutaneous electrical nerve stimulation

The high heterogeneity observed can be explained by the time the intervention was applied and the association with pharmacological analgesia. It was observed that the study of Cipriano et al. [24] applied TENS alone on the third day after surgery and this was not in association with pharmacological analgesia. Excluding this study, we found that TENS improves FVC if applied continuously in the first 24 hours postoperatively and if applied together with pharmacological analgesia ( $0.30 \mathrm{~L}, 95 \% \mathrm{CI}: 0.12$ to 0.48$)$.

We could not perform sensitivity analyzes in relation to analgesic doses and the route used for administration, due to the analgesic protocol that was used in the postoperative period differ between the included studies, and thus difficult to compare, as it can be shown in Table 2 .

\section{DISCUSSION}

\section{Summary of evidence}

In this study, we found that TENS associated with pharmacological analgesia promoted more pain relief compared to placebo TENS in patients after thoracic surgery in both the approach by thoracotomy and sternotomy. At sternotomy, was also more effective than controlled pharmacological analgesia for pain relief, but no significant effect on pulmonary function.

\section{Strengths and limitations of the review}

This study has several strong methodological points, such as formulating a specific research question, performing a sensitive, broad and systematic review of literature, with explicit and reproducible eligibility criteria, without language limitations, performed by two reviewers independently; selection of the studies, data extraction and analysis of the methodological quality of the articles included, also performed by two independent reviewers; and use of metaanalysis, increasing the power of evidence of the study, as opposed to the previous systematic reviews.

It was observed that the included RCTs were methodologically limited because none were in full the items noted in the assessment of risk of bias. In addition, doses of analgesics and route used for administration of the same in the postoperative period were different between the studies included, which can cause differences in results in pain relief. Because of these methodological differences, the few studies and the small number of patients included, the analysis of sensitivity to pain medications has been damaged. Nevertheless, this study demonstrated the beneficial role of TENS in reducing pain when combined with pharmacological analgesia, as in the included studies there was a control group that received the same analgesic intervention group, differing only in the intervention received.

Still, the studies included in systematic review included different types of surgical procedures, which can cause different mechanisms of injury and thus may interfere with the perception of postoperative pain. However, in studies of patients who underwent cardiac surgery has shown that there is no relationship between pain and the type of surgical procedure $[3,6]$. Therefore, the meta-analyzes were performed separately for the surgical approach (thoracotomy or sternotomy), since this can produce different levels of pain [2], regardless of the type of surgical procedure.

It has been shown that TENS associated with pharmacological analgesia compared to placebo TENS associated with pharmacological analgesia promotes greater reduction in pain after thoracic surgery, both in pulmonary surgery via posterolateral thoracotomy and cardiac surgery via median sternotomy. This is consistent with the study Freynet \& Falcoz [10], which showed the additional benefit of TENS for pain relief when combined with pharmacological analgesia after thoracotomy.

Several studies have shown that TENS acts to relieve pain mainly by two mechanisms of action: modulation of nociceptive input signals in the dorsal horn of the spinal cord via peripheral stimulation of large myelinated nerve fibers and type A, and the release of endogenous opioids have analgesic effect. These two mechanisms come into play during TENS application and its effect remains even after the completion of the application [25]. In thoracic 
surgery, TENS can be applied in appropriate dermatomes related to the incision area, giving effect directly on the site of origin of pain, which may amplify the analgesic effects observed.

In this systematic review, TENS associated with pharmacological analgesia compared to placebo TENS produced no change in FVC after median sternotomy. This may be due to the small number of studies included in this analysis ( 2 articles, $n=95$ ), generating a wide confidence interval. It is possible that more studies with larger number of patients included and greater statistical power analysis to occur in the modification of this result, so there is no conclusive evidence about the effectiveness of TENS on pulmonary function after median sternotomy.

\section{Comparisons with other reviews}

Freynet \& Falcoz [10] also conducted a systematic review on the subject. However, this study included only nine RCTs applied TENS postoperative thoracotomy only, while the present review included 12 articles that applied TENS in the postoperative period of thoracic surgery with either approach by thoracotomy and sternotomy. Moreover, the authors limited the search for articles in English, while the current revision showed no limitation language. The present review also presents the advantage of performing meta-analysis, increasing the power of the evidence generated. Besides, the meta-analyzes took into consideration the type of surgical approach used in the included studies. This quantitative data analysis was not performed by the authors.

For these reasons, some studies included in the review Freynet \& Falcoz [10] were excluded from this review, or do not meet the eligibility criteria or due to incomplete data prevents statistical analysis. Another positive aspect of this study was reviewed by two independent investigators in all phases of research and presents the evaluation of risk of bias of included studies. Therefore, our study provides a greater level of evidence in relation to existing evidence and evidence updated literature search performed until August 2011, in contrast to the search performed by other authors, which was until May 2009.

\section{CONCLUSION}

Through this systematic review and meta-analysis of RCTs can be concluded that TENS provides additional effect of pharmacological analgesia, as promoted greater pain relief compared to placebo TENS in patients after thoracic surgery, both in approach by thoracotomy and sternotomy. At sternotomy, was also more effective than controlled pharmacological analgesia for pain relief, but no significant effect on pulmonary function. TENS may be recommended as additional treatment for pain relief in thoracic surgery.
However, due to low methodological quality and small sample size of included studies, further RCTs are needed, with larger numbers of patients and greater methodological rigor to expand the power of information.

\section{ACKNOWLEDGMENTS}

This work was supported in part by the National Council for Scientific and Technological Development (CNPq Conselho Nacional de Desenvolvimento Científico e Tecnológico) and the Coordination of Improvement of Higher Education Personnel (CAPES - Coordenação de Aperfeiçoamento de Pessoal de Nível Superior).

\section{REFERENCES}

1. Costa IA. História da cirurgia cardíaca brasileira. Rev Bras Cir Cardiovasc. 1998;13(1):1-7.

2. Benedetti F, Amanzio M, Casadio C, Cavallo A, Cianci R, Giobbe R, et al. Control of postoperative pain by transcutaneous electrical nerve stimulation after thoracic operations. Ann Thorac Surg. 1997;63(3):773-6.

3. Giacomazzi CM, Lagni VB, Monteiro MB. A dor pósoperatória como contribuinte do prejuízo na função pulmonar em pacientes submetidos à cirurgia cardíaca. Rev Bras Cir Cardiovasc. 2006;21(4):386-92.

4. Forster EL, Kramer JF, Lucy SD, Scudds RA, Novick RJ. Effect of TENS on pain, medications, and pulmonary function following coronary artery bypass graft surgery. Chest. 1994;106(5):1343-8.

5. Baumgarten MC, Garcia GK, Frantzeski MH, Giacomazzi CM, Lagni VB, Dias AS, et al. Pain and pulmonary function in patients submitted to heart surgery via sternotomy. Rev Bras Cir Cardiovasc. 2009;24(4):497-505.

6. Mueller XM, Tinguely F, Tevaearai HT, Revelly JP, Chioléro $\mathrm{R}$, von Segesser LK. Pain location, distribution, and intensity after cardiac surgery. Chest. 2000;118(2):391-6.

7. Melzack R, Wall PD. Pain mechanisms: a new theory. Science. 1965;150(3699):971-9.

8. Gregorini C, Cipriano Junior G, Aquino LM, Branco JN, Bernardelli GF. Short-duration transcutaneous electrical nerve stimulation in the postoperative period of cardiac surgery. Arq Bras Cardiol. 2010;94(3):325-31.

9. Stubbing JF, Jellicoe JA. Transcutaneous electrical nerve stimulation after thoracotomy. Pain relief and peak expiratory flow rate--a trial of transcutaneous electrical nerve stimulation. Anaesthesia. 1988;43(4):296-8. 
10. Freynet A, Falcoz PE. Is transcutaneous electrical nerve stimulation effective in relieving postoperative pain after thoracotomy? Interact Cardiovasc Thorac Surg. 2010;10(2):283-8.

11. Higgins J, Green S. Cochrane handbook for systematic reviews of interventions 5.0 ed. Chichester:John Wiley \& Sons;2011.

12. Moher D, Liberati A, Tetzlaff J, Altman DG. Preferred reporting items for systematic reviews and meta-analyses: the PRISMA statement. Int J Surg. 2009;8(5):336-41.

13. Robinson KA, Dickersin K. Development of a highly sensitive search strategy for the retrieval of reports of controlled trials using PubMed. Int J Epidemiol. 2002;31(1):150-3.

14. Rooney SM, Jain S, Goldiner PL. Effect of transcutaneous nerve stimulation on postoperative pain after thoracotomy. Anesth Analg. 1983;62(11):1010-2.

15. Bayindir O, Paker T, Akpinar B, Erenturk S, Askin D, Aytac A. Use of transcutaneous electrical nerve stimulation in the control of postoperative chest pain after cardiac surgery. $\mathrm{J}$ Cardiothorac Vasc Anesth. 1991;5(6):589-91.

16. Dontaille M, Reeves B. TENS and pain control after coronary artery bypass surgery. Physiotherapy. 1997;83(10):510-6.

17. Navarathnam RG, Wang IY, Thomas D, Klineberg PL. Evaluation of the transcutaneous electrical nerve stimulator for postoperative analgesia following cardiac surgery. Anaesth Intensive Care. 1984;12(4):345-50.

18. Rooney SM, Jain S, McCormack P, Bains MS, Martini N, Goldiner PL. A comparison of pulmonary function tests for postthoracotomy pain using cryoanalgesia and transcutaneous nerve stimulation. Ann Thorac Surg. 1986;41(2):204-7.

19. Chandra A, Banavaliker JN, Das PK, Hasti S. Use of transcutaneous electrical nerve stimulation as an adjunctive to epidural analgesia in the management of acute thoracotomy pain. Indian J Anaesth. 2010;54(2):116-20.

20. Erdogan M, Erdogan A, Erbil N, Karakaya HK, Demircan A.
Prospective, Randomized, Placebo-controlled Study of the Effect of TENS on postthoracotomy pain and pulmonary function. World J Surg. 2005;29(12):1563-70.

21. Liu YC, Liao WS, Lien IN. Effect of transcutaneous electrical nerve stimulation for post-thoracotomic pain. Taiwan Yi Xue Hui Za Zhi. 1985;84(7):801-9.

22. Solak O, Turna A, Pekcolaklar A, Metin M, Sayar A, Solak O, et al. Transcutaneous electric nerve stimulation for the treatment of postthoracotomy pain: a randomized prospective study. Thorac Cardiovasc Surg. 2007;55(3):182-5.

23. Warfield CA, Stein JM, Frank HA. The effect of transcutaneous electrical nerve stimulation on pain after thoracotomy. Ann Thorac Surg. 1985;39(5):462-5.

24. Cipriano G Jr, Camargo Carvalho ACC, Bernardelli GF, Tayar Peres PA. Short-term transcutaneous electrical nerve stimulation after cardiac surgery: effect on pain, pulmonary function and electrical muscle activity. Interact Cardiovasc Thorac Surg. 2008;7(4):539-43.

25. Emmiler M, Solak O, Kocogullari C, Dundar U, Ayva E, Ela Y, et al. Control of acute postoperative pain by transcutaneous electrical nerve stimulation after open cardiac operations: a randomized placebo-controlled prospective study. Heart Surg Forum. 2008;11(5):E300-3.

26. Ferraz FS, Moreira CMC. Eletroanalgesia com utilização de TENS no pós-operatório de cirurgia cardíaca. Fisioter Mov. 2009;22(1):133-9.

27. Luchesa CA, Greca FH, Guarita-Souza LC, dos Santos JL, Aquim EE. The role of electroanalgesia in patients undergoing coronary artery bypass surgery. Rev Bras Cir Cardiovasc. 2009;24(3):391-6.

28. Solak O, Emmiler M, Ela Y, Dundar U, Koçoiullari CU, Eren $\mathrm{N}$, et al. Comparison of continuous and intermittent transcutaneous electrical nerve stimulation in postoperative pain management after coronary artery bypass grafting: a randomized, placebo-controlled prospective study. Heart Surg Forum. 2009;12(5):E266-71. 